\title{
Stimulated parotid gland flow rates in healthy, elderly dentulous and edentulous individuals
}

\author{
Charles F. Streckfus, DDS, MA, ${ }^{a}$ L. Jackson Brown, DDS, PhD, ${ }^{b}$ \\ Jonathan A. Ship, DMD, ${ }^{c}$ and Janet Brunelle, MS $^{d}$ \\ National Institutes of Health, National Institute of Dental Research, Bethesda, Md., and \\ University of Michigan, School of Dentistry, Ann Arbor, Mich.
}

\begin{abstract}
The use of dentures has been associated with increased stimulated parotid salivary flow rates (SPFR). A comparison of SPFRs was made between dentulous subjects having $20+$ teeth $(n=190)$ and edentulous individuals $(n=67)$. Two diff erent populations were selected, a white group from the Baltimore Longitudinal Study of Aging and an African-American group from the Washington Village Medical Center in Baltimore. Each group was healthy and unmedicated and had a mean age of 70.2 years. SPFR was determined with a Carlson-Crittenden cup and $2 \%$ citrate for stimulation. The edentulous subjects did not wear their dentures during salivary collection. The results indicated a significantly lower SPFR in dentate individuals compared with edentulous subjects $(p<0.01)$. Dentulous men also had a lower SPFR than edentulous men $(p<0.04)$. In addition, a pre- and postsurgical evaluation of 10 individuals who underwent full mouth tooth extractions revealed no differences in SPFR. These results suggest that edentulism per se does not have a deleterious effect on stimulated parotid salivary flow rates. (J PROSTHET DENT 1993;70:496-9.)
\end{abstract}

$\mathrm{T}$ The importance of normal salivary gland function and its relationship to oral health has been documented. ${ }^{1}$ Saliva has important physiologic relationships to speech, swallowing, and digestion. ${ }^{2}$ In edentulous individuals, saliva is necessary for the retention of complete dentures and the protection of the denture-bearing tissues. ${ }^{3}$

There is limited information about the effects of the loss of teeth and wearing of a removable prosthesis on salivary flow rates. In 1980 , Gabay ${ }^{4}$ reported no differences in stimulated whole salivary flow rates in 11 elderly individuals who went through the transition from dentate to edentulism, but found a significant increase in salivary flow on insertion of the dentures. The mean postinsertion flow rate was $2 \mathrm{ml} /$ minute compared with $0.75 \mathrm{ml} /$ minute during the pre- and postsurgical states. One year after denture insertion, Gabay resampled the 11 individuals and found the stimulated whole salivary flow rates even greater. ${ }^{4}$

Jensen et $\mathrm{a}^{5}$ examined two individuals who underwent full mouth tooth extractions and fabrication of complete removable prostheses and found increases in stimulated

Presented at the 7 ist Conference of the International Association of Dental Research, Chicago, Ill.

aSenior Staff Fellow, Epidemiology and Oral Disease Prevention Program (EODPP).

birector, EODPP

Associate Professor, Director, Hospital Dentistry, University of

Michigan School of Dentistry.

dSenior Scientist, FODPP.

$10 / 1 / 50413$ whole and stimulated parotid gland salivary flow rates after the insertion of the dentures and during mastication. In addition, there was an increase of whole and parotid salivary output on the ipsilateral side compared with the contralateral side during chewing. ${ }^{5}$

There are few published data about larger populations and the relationship of parotid salivary flow to dentate status and the loss of teeth is poorly understood. This study investigated the effects of long-term edentulism on stimulated parotid flow rates (SPFR) in two different elderly populations, one white and one African-American.

\section{METHODS}

\section{Populations}

Baltimore Longitudinal Study of Aging (BLSA). The first population consisted of volunteer participants in the oral physiology component of the Baltimore Longitudinal Study of Aging. ${ }^{6,7}$ These participants were community dwelling, ambulatory, elderly (65 years of age and older with a mean population age of 70.2 years) white individuals of a middle socioeconomic class. They were healthy and not taking any prescription medications. The subjects were divided into two groups: one group included dentulous individuals with 20 or more teeth and in the other group were edentulous individuals. There were 161 subjects in the dentate group (62 women and 99 men) and 38 ( 13 women and $25 \mathrm{men}$ ) in the edentulous group. In addition, all of the edentulous individuals had worn dentures for more than 10 years. 

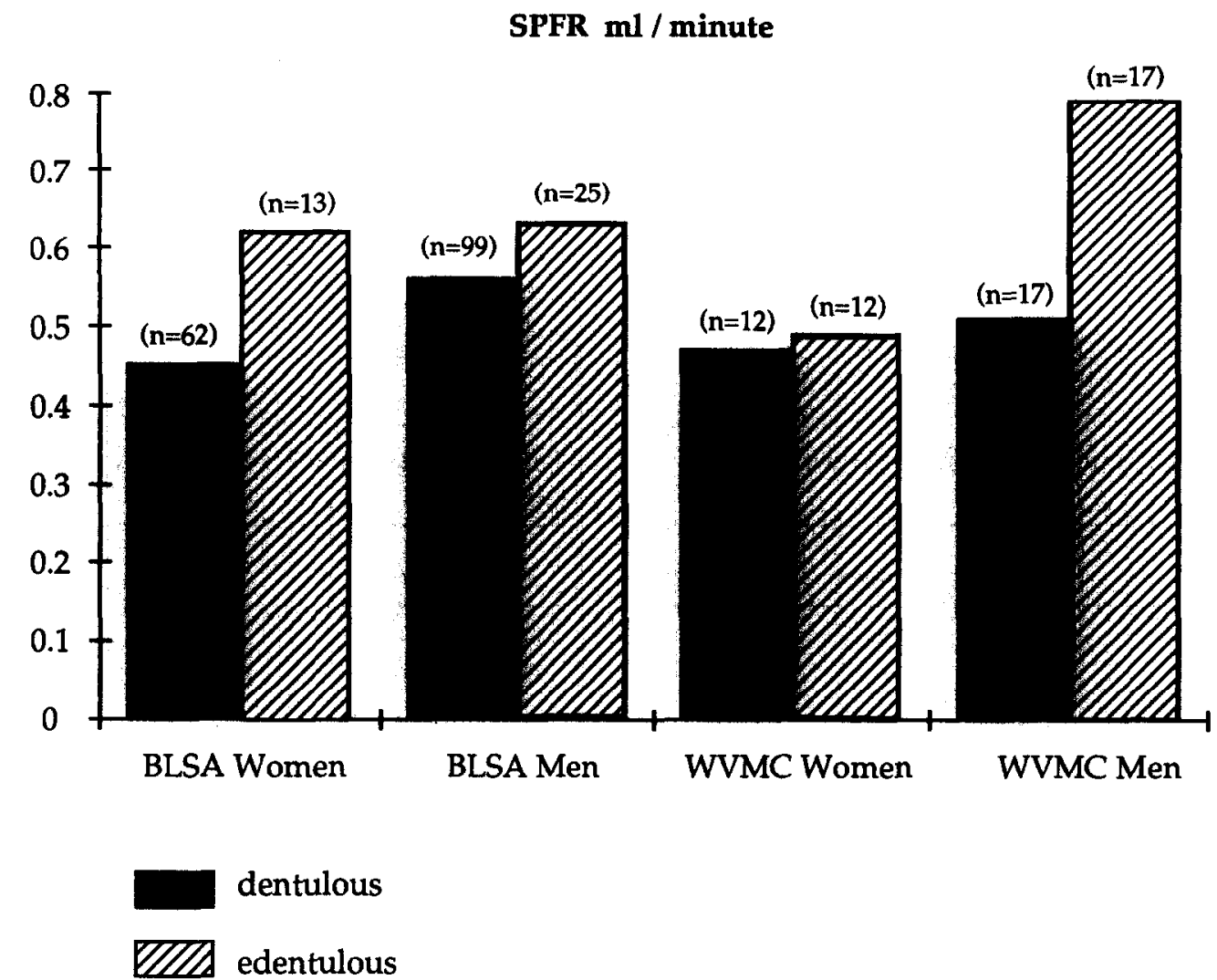

Fig. 1. SPFR in healthy, unmedicated white and African-American men and women, dentulous and edentulous individuals. $\mathrm{SPFR}=$ mean value. BLSA, Baltimore longitudinal study of aging; WVMC Washington Village Medical Center.

Washington Village Medical Center (WVMC). The second group consisted of African-Americans who resided in the southwest section of Baltimore City, Maryland. All of the participants were ambulatory, elderly patients (65 years of age and older with a mean population age of 70.2 years) who sought routine medical and dental care at the Washington Village Medical Center. They were healthy and not taking any prescription medications. All of the participants from the WVMC were of a low socioeconomic class. Detailed demographic and social characteristics have been reported. ${ }^{8}$

There were 12 women and $17 \mathrm{men}$ in both the edentulous and the dentate groups. The criteria for the two groups were identical to the BLSA population.

In addition, 10 individuals from the WVMC (four women and six men, mean age 70.4 years) with unrestorable teeth as a result of multiple caries or untreatable periodontal disease were examined before thev underwent full mouth tooth extractions. These subjects were generally healthy and were not taking any prescription or nonprescription medications and had at least five teeth that required extraction. SPFR were assessed 1 week before surgery, 6 months after surgery, and before insertion of their complete dentures.

\section{Saliva collection}

Saliva was collected from each subject's parotid gland between the hours of $8 \mathrm{AM}$ and noon to control circadian variances. ${ }^{9}$ Subjects did not eat, drink, rinse, or perform oral hygiene for at least 2 hours before collection, and the patient's dentures were removed before testing. Saliva was collected by one investigator in the BLSA population and by a second investigator in the WVMC population.

The Carlson-Crittenden cup was used to collect the saliva. ${ }^{10,11}$ The Stenson's duct was isolated and the CarlsonCrittenden cup was positioned over the ductal orifice. Stimulated saliva flow was observed for a 2-minute equilibrium period followed by a 2-minute period of actual total collection. A $2 \%$ citric acid solution was applied to the dorsum of the tongue every 30 seconds during the 2-minute collection and 2-minute equilibrium periods. ${ }^{12}$ Samples were collected in preweighed plastic tubes and salivary output was determined gravimetrically.

\section{Statistical techniques}

Statistical analyses were performed with the SAS statistical software package (SAS Institute Inc., Cary, N.C.). Descriptive statistics on SPFR were run for dentate and edentulous individuals for gender and each population. To 
Table I. Descriptive statistics on stimulated parotid flow rates in dentulous and edentulous individuals

\begin{tabular}{|c|c|c|c|c|c|c|}
\hline \multirow[b]{2}{*}{ Groups } & \multicolumn{3}{|c|}{ Dentate } & \multicolumn{3}{|c|}{ Edentulous } \\
\hline & $\mathbf{n}$ & $\begin{array}{c}\text { SPFR } \\
\mathrm{mL} / \mathrm{min}\end{array}$ & SD & $\mathbf{n}$ & $\underset{\mathrm{mL} / \mathrm{min}}{\mathrm{SPFR}}$ & SD \\
\hline Women BLSA & 62 & 0.45 & \pm 0.34 & 13 & 0.62 & \pm 0.37 \\
\hline Men BLSA & 99 & 0.56 & \pm 0.41 & 25 & 0.63 & \pm 0.40 \\
\hline Women WVMC & 12 & 0.47 & \pm 0.26 & 12 & 0.49 & \pm 0.21 \\
\hline Men WVMC & 17 & 0.51 & \pm 0.21 & 17 & 0.79 & \pm 0.54 \\
\hline
\end{tabular}

Table II. Results of multivariate ANOVA with interaction terms

\begin{tabular}{lccc}
\multicolumn{1}{c}{ Source } & $\begin{array}{c}\text { Sum of } \\
\text { squares }\end{array}$ & F-Ratio & P-Value \\
\hline $\begin{array}{l}\text { Gender } \\
\text { Population }\end{array}$ & 0.784 & 5.51 & 0.02 \\
$\quad$ BLSA vs WVMC & 0.091 & 0.64 & 0.96 \\
$\begin{array}{l}\text { Status Dentate } \\
\quad \text { vs edentulous }\end{array}$ & 0.774 & 5.44 & 0.03 \\
$\begin{array}{l}\text { Gender } \times \text { population } \\
\text { Population } \times \text { status }\end{array}$ & 0.071 & 0.50 & 0.54 \\
Gender $\times$ status & 0.029 & 0.65 & 0.64 \\
\hline
\end{tabular}

determine whether the data could be combined across the two populations, an analysis of variance (ANOVA) procedures general linear measure (PROC GLM) ${ }^{13}$ was performed with three classification variables: population gender (BLSA versus WVMC), dentate status (dentate versus edentulous), and all two-way interactions defined by these main-effect variables. In the absence of either a significant main effect of population or a significant interaction effect between population and dentate status, the data were combined across the two populations.

A two-way ANOVA was then used to compare mean levels of SPFR among men and women and among dentate and edentulous individuals. Significant overall group differences, for example, main effects of gender or dentate status, were also tested with the Bonferroni (Dunn) $t$-test. The more comparisons made between groups, the more likely is the inference that a relationship exists when it truly does not. Multiple comparisons thus artificially inflate the type I error of each of the comparisons; therefore, the Bonferroni procedure was used to correct for multiple comparisons in the analyses. ${ }^{14}$

For the final set of analyses related to the pre- and postsurgical data set, the $t$-test statistic was used for matchedpair design to test for significant differences in SPFR before and after surgical intervention. The level of significance for all analyses was $p<0.05$.

\section{RESULTS}

timulated parotid flow rates for both BLSA and WVMC inen and women, by dentate status group, are illustrated in
Table III. Results of 2-way ANOVA with main effects only

\begin{tabular}{lccc}
\hline \multicolumn{1}{c}{ Source } & $\begin{array}{c}\text { Sum of } \\
\text { squares }\end{array}$ & F-Ratio & P-Value \\
\hline Gender & 0.785 & 5.41 & 0.02 \\
Dentate status & 0.865 & 6.16 & 0.01 \\
$\quad$ Dentate vs edentate & & & \\
\hline
\end{tabular}

Fig. 1. With the exception of greater SPFR among edentulous WVMC men (Table I), there was little variation of flow rates across the groups. Results from the multivariate ANOVA demonstrated that data from both populations could be combined (Table II). It is likely that the absence of a significant effect of population in these models reflects the absence of racial differences in mean SPFR because each population represents a different race.

After the data from the two populations were combined, the effect of gender and dentate status on SPFR was examined. The results indicated significant overall main effects of gender and dentate status (Table III). Edentulous individuals had a higher mean SPFR than did the dentate individuals (in data controlled for gender) (Table IV). Similarly, men had higher flow rates than did women (in data adjusted for dentate status). The significant differences among groups remained after adjustment for multiple comparisons.

An analysis of SPFR in 10 individuals before full mouth tooth extractions and 6 months after surgery, before the insertion of dentures, is displayed in Table V. The mean number of teeth extracted was 8.4 with a range of 5 to 20 . The results demonstrate no statistical differences in SPFR due to the extraction of teeth.

\section{DISCUSSION}

The results of this investigation showed a significantly higher SPFR in edentulous compared with dentulous individuals. These elevated SPFR in edentulous subjects tend to agree with the elevated whole and parotid salivary flow rates reported in the experimental studies by Gabay, ${ }^{4}$ and Jenson et al. ${ }^{5}$

One possible explanation for the elevated SPFR in edentulous individuals may be an adaptive result of the chronic stimulation of the mechanoreceptors located under 
Table IV. Comparison of mean stimulated parotid flow rates by gender and dentate status

\begin{tabular}{lccc}
\hline Source & $\begin{array}{c}\text { Adjusted } \\
\text { mean }\end{array}$ & $\begin{array}{c}\text { standard } \\
\text { error }\end{array}$ & $\boldsymbol{p}$-Value \\
\hline Men & 0.62 & 0.03 & \}$<0.02$ \\
Women & 0.51 & 0.04 & \\
Edentulous & 0.63 & 0.05 & $<<0.02$ \\
Dentulous & 0.50 & 0.03 & \\
\hline
\end{tabular}

Table V. Pre- and postsurgical stimulated parotid flow rates

\begin{tabular}{|c|c|c|c|c|}
\hline \multicolumn{2}{|c|}{ Presurgery } & \multicolumn{2}{|c|}{ Postsurgery } & \multirow[b]{2}{*}{$\underset{p \text {-values }}{t \text {-Test }}$} \\
\hline $\begin{array}{c}\text { SPFR } \\
\mathrm{mI} / \mathrm{min}\end{array}$ & SD & $\begin{array}{c}\text { SPFR } \\
\mathrm{mI} / \mathrm{min}\end{array}$ & SD & \\
\hline 0.41 & \pm 0.28 & 0.38 & \pm 0.19 & n.s. \\
\hline
\end{tabular}

the denture base, which initiated an enhanced salivary reflex through pressure mediated by the dentures over the years. Because saliva was collected with dentures removed, it is unknown what effect long-term use of removable prostheses has on salivary function. Overall, edentulous individuals had higher SPFR than dentulous subjects, and this was most apparent in edentulous men from the WVMC (Fig. 1). Most of these subjects had little dental treatment in the past. A clinical observation of these dentures (WVMC men) revealed many old, ill-fitting dentures with homemade repairs. A majority of these dentures were the "vulcanized" type typical of the 1940 s, with inadequate retention and no evidence of ever being rebased for proper fit. It is possible that poor approximation of dentures to oral mucosa could produce chronic stimulation and irritation, which could account for the increased SPFR in this group.

Another interesting finding of the study was that SPFR were not different before or after full mouth tooth extractions, which correlates with the report of Jenson et al. ${ }^{5}$ The data suggest that the removal of the dentition per se, along with the periodontal ligaments and associated mechanoreceptors, does not influence an individual's ability to produce stimulated parotid saliva.

These findings along with previous studies demonstrate that extraction of the dentition and the long-term use of removable prostheses do not produce detrimental effects on an individual's capacity to produce adequate quantities of saliva. Although edentulous individuals may exhibit higher elevated SPFR, these rates are still within the normal range of salivary gland flow rates reported by Mande ${ }^{15}$ and Ship et al. ${ }^{16}$ Further research is still required to determine the underlying causes for the increase in salivation in edentulous individuals who wear dentures.

\section{REFERENCES}

1. Mandel I. The role of saliva in maintaining oral homeostasis. J Am Dent Assoc 1989;119:298-304.

2. Mandel I. Salivary diagnosis: more than a lick and a promise. J Am Dent Assoc, 1993;124:85-7.

3. Edgertun M, Tabak L, Levine M. Saliva: a significant factor in removable prosthodontic treatment. J PROSTHET DENT 1987;57:57-66.

4. Gabay E. Flow rate, sodium and potassium concentration in mixed saliva of complete denture wearers. J Oral Rehabil 1980;7:435-43.

5. Jensen J, Brodin P, Ørstavik J. Parotid salivary flow rates in two patients during immediate denture treatment. J Oral Rehabil 1991; 18:155-62.

6. Baum B. Characteristies of participants in the oral physiology component of the Baltimore longitudinal study of aging. Community Dent Oral Epidemiol 1981;9:128-34.

7. Shock N, Gruelich R, Andres R, et al. Normal human aging: the Baltimore longitudinal study of aging. Bethesda, Md: National Institutes of Health, Publ No. 84-2450, November 1984.

8. Strahl R, Streckfus C, Greene B. The periodontal condition of Baltimore's ambulatory non-institutionalized elderly. J Md State Dent As soc $1986 ; 29: 64-7$.

9. Dawes C. Rhythms in salivary flow rate and composition. Int J Chronobiol 1974;2:253-79.

10. Heft M, Baum B. Unstimulated and stimulated parotid salivary flow rates in individuals of different ages. $J$ Dent Res 1984;63:1182-5.

11. Baum BJ. Evaluation of stimulated parotid flow rates in different age groups. J Dent Res 1981;60:1292-6.

12. Tylenda C, Ship J, Fox P, Baum B. Evaluation of submandibular salivary flow rate in different age groups. J Dent Res 1988;67:1225-8.

13. SAS/STAT user's guide, version 6, vol 2. Cary, NC: 4th ed. SAS Institute, 1990;898.

14. Kleinbaum D, Kupper L, Muller K. Applied regression analysis and other multivariable methods. Boston: PWS-Kent Publishing Co, 1988;361-5.

15. Mandel I. Sialochemistry in diseases and clinical situations affecting salivary glands. CRC Crit Rev Clin Lab Sci 1980;12:321-66.

16. Ship J, Fox P, Baum B. How much saliva is enough? Normal function defined. J Am Dent Assoc 1991;122:63-9.

Reprint requests to:

Dr. Charles F. Streckfus

EODPP/NIDR/NIH

WESTWOOD BUILDING, ROOM 718C

5333 WESTBARD AVE.

BETHESDA, MD 20892

\section{Contributing authors}

Stephen Marcus, PhD, Senior Epidemiologist, Epidemiology and Oral Disease Prevention Program (EODPP); Richard Oldakowski, BA, Chief Computer Programmer, EODPP; and Tullio Albertini, DDS, MPH, Assistant Director, EODPP. 